\title{
O INHANDUVÁ (PROSOPIS AFFINIS SPRENG.) NO RIO GRANDE DO SUL. 4-ASPECTOS BOTÂNICO-VEGETACIONAIS E MORFOMÉTRICOS DO PARQUE DO LORETO, SÃO VICENTE DO SUL ${ }^{1}$
}

\author{
JOSÉ NEWTON CARDOSO MARCHIORI² MIGUEL ANTÃO DURLO $^{3}$ \\ FABIANO DA SILVA ALVES ${ }^{4}$
}

\section{RESUMO}

Composto por 50 indivíduos de Prosopis affinis Spreng. (Fabaceae), o parque do Loreto apresenta os inhanduvás de maior altura e diâmetro à altura do peito do Rio Grande do Sul. Outro aspecto distinto reside na copa, que varia de hemisférica até em forma de sombrinha.

Palavras-chave: Prosopis affinis, Fitogeografia, Rio Grande do Sul, Dendrologia, morfometria de árvores.

\section{SUMMARY}

[Prosopis affinis Spreng. in Rio Grande do Sul state, Brazil. 4 - Some botanical, vegetacional and morphometric features of Loreto's Nandubay thicket, municipality of São Vicente do Sul].

Compoud by 50 trees, the Loreto's Nandubay thicket show the highest trees and most thick boles of Prosopis affinis Spreng. in the state of Rio Grande do Sul, Brazil. The umbrella-like or hemispheric crowns are also tree morphology peculiarities.

Key words: Prosopis affinis, Phytogeography, Rio Grande do Sul state - Brazil, Dendrology, tree morphometry.

\section{INTRODUÇÃO}

Descrito em artigo anterior ${ }^{5}$, o parque de inhanduvá do Loreto (São Vicente do Sul - RS) é presentemente investigado sob os enfoques dendrológico-vegetacional e morfométrico, com vistas ao exame de singularidades fisionômicas reconhecidas tanto por comparação com outras áreas de ocorrência no Estado, como, inclusive, entre os próprios indivíduos da população em estudo. Além de conter alguns dos inhanduvás

1 Recebido em 30-01-2011 e aceito para publicação em 15-2-2011.

2 Engenheiro Florestal, Dr. Professor Titular do Departamento de Ciências Florestais, UFSM. Bolsista de Produtividade em Pesquisa ( $\mathrm{CNPq}$ - Brasil).

3 Engenheiro Florestal, Dr. Professor Adjunto do Departamento de Ciências Florestais, UFSM.

4 Biólogo, MSc. Doutorando do Programa de Pós-Graduação em Engenharia Florestal, UFSM. Professor da Universidade da Região da Campanha - URCAMP (Alegrete, RS).

5 MARCHIORI, J.N.C.; ALVES, F. da S.; PAZ, E.A. $O$ Inhanduvá (Prosopis affinis Spreng.) no Rio Grande do Sul. 3 - Parque da Cabanha do Loreto, São Vicente do Sul. Balduinia, Santa Maria, n. 25, p. 22-31, 2010. de maior porte e, provavelmente, mais longevos do Rio Grande do Sul - fato que depõe favoravelmente à origem natural das árvores -, o parque de inhanduvá do Loreto também chama atenção pelas formas variadas de copa, sobretudo em indivíduos velhos, que fogem aos padrões "amplo e estendido" , achatado 7 ou corimbiforme ${ }^{8}$, costumeiramente referidos na literatura botânica para a espécie.

\section{MATERIAL E MÉTODOS}

O presente estudo foi realizado no parque de inhanduvá (Prosopis affinis Spreng.) da Cabanha do Loreto, em São Vicente do Sul, centro-oeste do Rio Grande do Sul. A área, definida pelas coordenadas de $29^{\circ} 42^{\prime} 14^{\prime \prime} \mathrm{S}$ e $54^{\circ} 56^{\prime}$ $05^{\prime \prime}$, situa-se no topo de suave coxilha, distando cerca de $1500 \mathrm{~m}$ ao sul da estrada RS 241, e $2,3 \mathrm{~km}$ a leste do rio Jaguari.

\footnotetext{
6 Definição de Tortorelli (1956).

Copa "chata", segundo BURKART (1987).

8 MARCHIORI, J.N.C. Dendrologia das Angiospermas. Leguminosas. Santa Maria: Ed. UFSM, 1997. p. 42.
} 
O solo da região, do tipo Argissolo Bruno Acinzentado (Streck et al., 2008), apresenta afloramentos de pequenos blocos de rocha junto aos inhanduvás.

$\mathrm{O}$ clima regional corresponde ao tipo $\mathrm{Cfa}$, de Köppen-Geiger, apresentando chuvas regulares em todos os meses do ano, temperatura do mês mais frio entre $3-18^{\circ} \mathrm{C}$, e verões com temperatura média do mês mais quente superior a $22^{\circ} \mathrm{C}$ (Moreno, 1961). De acordo com Nimer (1977), o clima corresponde ao tipo Mesotérmico Brando Super-Úmido, sem estação seca.

Das árvores, foram coletados ramos férteis em Dezembro de 2010 e Janeiro de 2011, com vistas à definição de caracteres botânicodendrológicos, notadamente de folhas, peças florais e frutos. Parte deste material serviu para a confecção de exsicatas, que foram incorporadas ao acervo do Herbário do Departamento de Ciências Florestais da Universidade Federal de Santa Maria. Na medição de carateres botânicos usou-se régua militrada e lupa de bolso, tipo conta-fios.

Para o levantamento da vegetação foram usadas estacas e uma trena de $30 \mathrm{~m}$, estendida ao longo do comprimento maior do parque e em posição aproximadamente central. Nas estacas extremas desta linha foram anotadas as coordenadas geográficas dos respectivos pontos, com GPS modelo Garmin Map 60 CSx.

Para a maioria dos inhanduvás anotou-se a distância relativa à trena, tomada perpendicularmente à mesma, bem como a distância entre este ponto e o início da linha, de modo a definir a localização espacial de cada indivíduo, em sua exata posição (Figura 1). No caso de árvores mais distantes dessa linha, o posicionamento geográfico foi definido por simples leitura no referido aparelho de GPS.

Devido à abertura da vegetação, optou-se por medir a altura total das árvores e a altura da primeira bifurcação (base da copa) com régua telescópica; o diâmetro do tronco à altura do peito (DAP) foi medido com fita diamétrica. Para cada um dos indivíduos anotaram-se, ainda, os raios de projeção de copa nos quatro pontos cardeais, usados para a definição do diâmetro médio de copa (Dc) de cada indivíduo e da respectiva área de copa (Ac). O conjunto de dados resultante do trabalho de campo, bem como as variáveis morfométricas geradas a partir dos mesmos, é apresentado na Tabela 1.

No escritório, os valores numéricos foram computados, obtendo-se, com o auxílio do programa SPSS, a estatística descritiva e a análise morfométrica, apresentados, conjuntamente, na Tabela 2, bem como os gráficos das Figuras 2 6. A análise morfométrica incluiu os seguintes parâmetros: diâmetro de copa (Dc), área de copa (Ac), altura de copa $(\mathrm{Hc})$, percentagem de copa $(\mathrm{Pc})$, formal de copa $(\mathrm{Fc})$ e grau de esbeltez do tronco (GE).

\section{ANÁLISE DE CARACTERES BOTÂNICOS}

O material botânico coletado no parque do Loreto corresponde, integralmente, ao descrito por Burkart (1940, 1967, 1987), Brussa \& Grela (2007), Izaguirre \& Beyhaut (2003), Nuñez \& Cantero (2006) e Tortorelli (1956), para Prosopis affinis Spreng. e um de seus binômios reduzido à sinonímia (Prosopis algarobilla Griseb.). Apesar do porte avantajado das árvores e de algumas diferenças morfométricas merecedoras de análise, o material botânico examinado corresponde ao inhanduvá, no tocante a aspectos qualitativos e quantitativos de folhas, flores e frutos.

No parque de São Vicente do Sul, os troncos das árvores, relativamente curtos e tortuosos, apresentam casca espessa e castanho-escura, com fissuras profundas. À semelhança do observado nos indivíduos do Jarau (Quaraí) e do Parque Estadual do Espinilho (Barra do Quaraí), os raminhos também são rígidos, castanhoacinzentados e armados de espinhos geminados, de $0,5-1,5 \mathrm{~cm}$ de comprimento.

As folhas, verde-amareladas, de $1-5 \mathrm{~cm}$ de comprimento e com pecíolo curto $(3-8 \mathrm{~mm})$, apresentam-se, geralmente, com um único par de pinas, salvo em raminhos jovens, onde tam- 


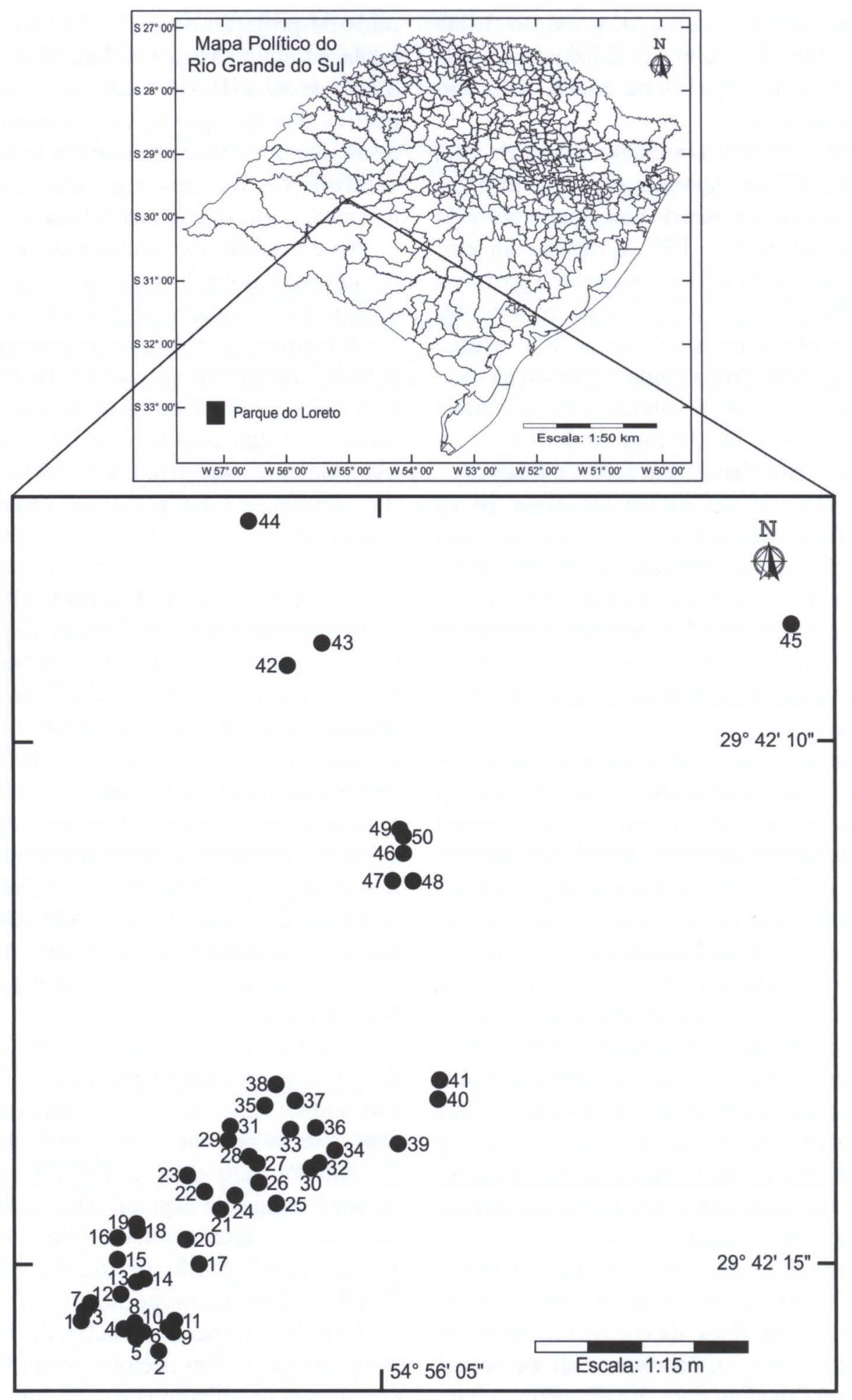

FIGURA 1 - Mapa de localização dos inhanduvás no Parque do Loreto, São Vicente do Sul - Rio Grande do Sul. 
TABELA 1 - Dados de campo e variáveis morfométricas dos inhanduvás do parque do Loreto.

\begin{tabular}{|c|c|c|c|c|c|c|c|c|c|c|c|c|c|}
\hline $\begin{array}{l}\mathbf{N} \\
\Downarrow \\
\end{array}$ & $\begin{array}{c}\text { DAP } \\
\text { cm }\end{array}$ & $\begin{array}{l}\mathbf{H} \\
\mathbf{m} \\
\end{array}$ & $\begin{array}{l}\mathbf{L} \\
\mathbf{m}\end{array}$ & $\begin{array}{l}\text { No } \\
\text { dm }\end{array}$ & $\begin{array}{l}\text { Le } \\
\text { dm }\end{array}$ & $\begin{array}{l}\text { Sul } \\
\text { dm }\end{array}$ & $\begin{array}{c}\text { Oe } \\
\text { dm }\end{array}$ & $\begin{array}{c}\text { De } \\
\text { m }\end{array}$ & $\begin{array}{l}\mathbf{A c} \\
\mathbf{m}^{2}\end{array}$ & $\begin{array}{c}\text { Hc } \\
\text { m }\end{array}$ & $\begin{array}{l}\text { Pc } \\
\%\end{array}$ & $\begin{array}{c}\mathbf{F c} \\
\text { adm. }\end{array}$ & $\begin{array}{c}\text { GE } \\
\text { adm. }\end{array}$ \\
\hline 1 & 36.7 & 3.52 & 1.62 & 28 & 22 & 14 & 16 & 4.0 & 12.57 & 1.90 & 53.9 & 2.11 & 9.59 \\
\hline 2 & 55.1 & 7.10 & 1.60 & 47 & 48 & 73 & 42 & 10.5 & 86.59 & 5.50 & 77.4 & 1.91 & 12.89 \\
\hline 3 & 27.6 & 4.48 & 1.34 & 15 & 20 & 15 & 32 & 4.1 & 13.20 & 3.14 & 70.1 & 1.31 & 16.23 \\
\hline 4 & 19.9 & 5.50 & 2.14 & 35 & -14 & 26 & 30 & 3.9 & 11.64 & 3.36 & 61.1 & 1.15 & 27.64 \\
\hline 5 & 27.9 & 6.50 & 2.70 & 45 & 27 & 48 & 24 & 7.2 & 40.72 & 3.80 & 58.5 & 1.89 & 23.30 \\
\hline 6 & 23.4 & 6.50 & 1.98 & 45 & 42 & 32 & 1 & 6.0 & 28.27 & 4.52 & 69.5 & 1.33 & 27.78 \\
\hline 7 & 18.2 & 4.36 & 1.65 & 33 & 46 & 37 & -8 & 5.4 & 22.90 & 2.71 & 62.2 & 1.99 & 23.96 \\
\hline 8 & 31.8 & 6.82 & 1.44 & 44 & 6 & 18 & 39 & 5.4 & 22.48 & 5.38 & 78.9 & .99 & 21.45 \\
\hline 9 & 26.8 & 4.71 & 1.76 & 24 & 48 & 35 & 20 & 6.4 & 31.67 & 2.95 & 62.6 & 2.15 & 17.57 \\
\hline 10 & 29.1 & 5.46 & 1.66 & 18 & 30 & 29 & 24 & 5.1 & 20.03 & 3.80 & 69.6 & 1.33 & 18.76 \\
\hline 11 & 34.7 & 5.84 & 1.72 & 48 & 24 & 6 & 51 & 6.5 & 32.67 & 4.12 & 70.5 & 1.57 & 16.83 \\
\hline 12 & 17.2 & 4.38 & 1.62 & 14 & 11 & 22 & 23 & 3.5 & 9.62 & 2.76 & 63.0 & 1.27 & 25.47 \\
\hline 13 & 36.4 & 5.33 & .70 & 35 & 27 & 44 & 45 & 7.6 & 44.77 & 4.63 & 86.9 & 1.63 & 14.64 \\
\hline 14 & 26.0 & 5.12 & 1.20 & 36 & 24 & 3 & 29 & 4.6 & 16.62 & 3.92 & 76.6 & 1.17 & 19.69 \\
\hline 15 & 46.4 & 4.47 & .70 & 39 & 38 & 34 & 44 & 7.8 & 47.17 & 3.77 & 84.3 & 2.06 & 9.63 \\
\hline 16 & 49.5 & 6.45 & 1.49 & 49 & 41 & 39 & 50 & 9.0 & 62.91 & 4.96 & 76.9 & 1.80 & 13.03 \\
\hline 17 & $\begin{array}{l}55.8 \\
\end{array}$ & 7.80 & 2.22 & 74 & 41 & 54 & 79 & 12.4 & 120.8 & 5.58 & 71.5 & 2.22 & 13.98 \\
\hline 18 & 40.3 & 5.44 & 1.00 & 36 & 47 & 38 & 17 & 6.9 & 37.39 & 4.44 & 81.6 & 1.55 & 13.50 \\
\hline 19 & 26.2 & 5.80 & 1.71 & 44 & 25 & 4 & 39 & 5.6 & 24.63 & 4.09 & 70.5 & 1.37 & 22.14 \\
\hline 20 & 26.9 & 4.29 & 1.66 & 37 & 13 & 14 & 23 & 4.4 & 14.86 & 2.63 & 61.3 & 1.65 & 15.95 \\
\hline 21 & 55.8 & 5.42 & .50 & 33 & 22 & 40 & 38 & 6.7 & 34.73 & 4.92 & 90.8 & 1.35 & 9.71 \\
\hline 22 & 30.7 & 5.43 & 2.05 & 32 & 33 & 27 & 32 & 6.2 & 30.19 & 3.38 & 62.3 & 1.83 & 17.69 \\
\hline 23 & 54.7 & 5.84 & 1.91 & 56 & 57 & 35 & 58 & 10.3 & 83.32 & 3.93 & 67.3 & 2.62 & 10.68 \\
\hline 24 & 30.2 & 5.02 & 1.54 & 42 & 24 & 38 & 32 & 6.8 & 36.32 & 3.48 & 69.3 & 1.95 & 16.62 \\
\hline 25 & 22.0 & 4.05 & 1.84 & 26 & 17 & 12 & 23 & 3.9 & 11.95 & 2.21 & 54.6 & 1.76 & 18.41 \\
\hline 26 & 12.8 & 3.27 & 1.45 & 16 & 17 & 17 & 16 & 3.3 & 8.55 & 1.82 & 55.7 & 1.81 & 25.55 \\
\hline 27 & 16.3 & 2.89 & .20 & 17 & 21 & 21 & 12 & 3.6 & 9.90 & 2.69 & 93.1 & 1.32 & 17.73 \\
\hline 28 & 56.0 & 5.96 & .20 & 52 & 47 & 38 & 44 & 9.1 & 64.33 & 5.76 & 96.6 & 1.57 & 10.64 \\
\hline 29 & 41.1 & 5.23 & .70 & 31 & 34 & 46 & 52 & 8.2 & 52.17 & 4.53 & 86.6 & 1.80 & 12.73 \\
\hline 30 & 49.8 & 4.69 & 1.67 & 28 & 0 & 37 & 55 & 6.0 & 28.27 & 3.02 & 64.4 & 1.99 & 9.42 \\
\hline 31 & 39.8 & 4.87 & 2.14 & 48 & 53 & 18 & 42 & 8.1 & 50.90 & 2.73 & 56.1 & 2.95 & 12.24 \\
\hline 32 & 43.3 & 6.70 & 1.55 & 35 & 20 & 60 & 56 & 8.6 & 57.41 & 5.15 & 76.9 & 1.66 & 15.47 \\
\hline 33 & 21.0 & 3.46 & .10 & 24 & 11 & 12 & 22 & 3.5 & 9.35 & 3.36 & 97.1 & 1.03 & 16.48 \\
\hline 34 & 46.5 & 5.84 & .50 & 37 & 34 & 46 & 49 & 8.3 & 54.11 & 5.34 & 91.4 & 1.55 & 12.56 \\
\hline 35 & 60.2 & 5.52 & 2.32 & 47 & 55 & 49 & 40 & 9.6 & 71.63 & 3.20 & 58.0 & 2.98 & 9.17 \\
\hline 36 & 37.8 & 5.86 & 1.95 & 59 & 48 & 53 & 58 & 10.9 & 93.31 & 3.91 & 66.7 & 2.79 & 15.50 \\
\hline 37 & 31.2 & 4.22 & 1.69 & 39 & 33 & 29 & 38 & 7.0 & 37.94 & 2.53 & 59.9 & 2.75 & 13.53 \\
\hline 38 & 30.5 & 3.95 & .30 & 34 & 27 & 32 & 29 & 6.1 & 29.22 & 3.65 & 92.4 & 1.67 & 12.95 \\
\hline 39 & 52.4 & 5.88 & 1.20 & 55 & 39 & 40 & 64 & 9.9 & 76.98 & 4.68 & 79.6 & 2.12 & 11.22 \\
\hline 40 & 32.4 & 4.86 & 1.85 & 41 & 33 & 43 & 50 & 8.4 & 54.76 & 3.01 & 61.9 & 2.77 & 15.00 \\
\hline 41 & 14.6 & 3.55 & 1.30 & 34 & 17 & 5 & 31 & 4.4 & 14.86 & 2.25 & 63.4 & 1.93 & 24.32 \\
\hline 42 & 42.0 & 4.16 & 1.36 & 34 & 37 & 43 & 44 & 7.9 & 49.02 & 2.80 & 67.3 & 2.82 & 9.90 \\
\hline 43 & 34.7 & 4.54 & .60 & 29 & 35 & 34 & 33 & 6.6 & 33.70 & 3.94 & 86.8 & 1.66 & 13.08 \\
\hline 44 & 37.3 & 5.79 & 2.33 & 34 & 28 & 32 & 37 & 6.6 & 33.70 & 3.46 & 59.8 & 1.89 & 15.52 \\
\hline 45 & 63.7 & 5.87 & 2.02 & 65 & 54 & 60 & 58 & 11.9 & 110.3 & 3.85 & 65.6 & 3.08 & 9.22 \\
\hline 46 & 74.0 & 8.50 & 1.60 & 70 & 75 & 69 & 73 & 14.4 & 161.7 & 6.90 & 81.2 & 2.08 & 11.49 \\
\hline 47 & 39.8 & 6.26 & 1.30 & 39 & 40 & 38 & 45 & 8.1 & 51.53 & 4.96 & 79.2 & 1.63 & 15.73 \\
\hline 48 & 8.9 & 3.13 & 1.40 & 9 & 13 & 16 & 16 & 2.7 & 5.73 & 1.73 & 55.3 & 1.56 & 35.17 \\
\hline 49 & 22.3 & 3.29 & 1.10 & 19 & 9 & 27 & 34 & 4.5 & 15.55 & 2.19 & 66.6 & 2.03 & 14.75 \\
\hline 50 & 28.9 & 5.93 & 1.66 & 34 & 38 & -4 & 41 & 5.5 & 23.33 & 4.27 & 72.0 & 1.28 & 20.52 \\
\hline
\end{tabular}

$\mathrm{N}$ = número do indivíduo de Inhanduvá; $\mathrm{DAP}=$ Diâmetro à altura do peito; $\mathrm{H}=$ Altura total da árvore; $\mathrm{L}=\mathrm{Altura}$ da primeira bifurcação, ou base da copa; $\mathrm{No}, \mathrm{Le}, \mathrm{Sul}, \mathrm{e} \mathrm{Oe}=$ Comprimento da projeção vertical da copa, nas direções Norte, Leste, Sul e Oeste; Dc = Diâmetro de copa; Ac = Área de projeção da copa; Hc = Altura da copa; Pc = Percentagem de copa; $\mathrm{Fc}=$ Formal de copa; GE $=$ Grau de esbeltez do tronco. 
TABELA 2 - Estatística descritiva.

\begin{tabular}{|l|c|c|c|c|c|}
\hline \multicolumn{1}{|c|}{$\begin{array}{c}\text { VARIÁVEL } \\
\Downarrow\end{array}$} & $\mathrm{N}$ & $\begin{array}{c}\text { Valor } \\
\text { mínimo }\end{array}$ & $\begin{array}{c}\text { Valor } \\
\text { máximo }\end{array}$ & $\begin{array}{c}\text { Valor } \\
\text { médio }\end{array}$ & $\begin{array}{c}\text { Desvio } \\
\text { padrão }\end{array}$ \\
\hline Diâmetro a 1.30m (cm) & 50 & 8.90 & 74.0 & 35.70 & 14.49 \\
\hline Altura total (m) & 50 & 2.89 & 8.5 & 5.20 & 1.21 \\
\hline Altura até a 1 ${ }^{\mathrm{a}}$ bifurcacão (m) & 50 & 0.10 & 2.7 & 1.44 & 0.61 \\
\hline Diâmetro da copa (m) & 50 & 2.7 & 14.4 & 6.84 & 2.589 \\
\hline Área de copa (m $\left.{ }^{2}\right)$ & 50 & 5.73 & 161.7 & 41.92 & 32.07 \\
\hline Comprimento de copa (m) & 50 & 1.73 & 6.90 & 3.75 & 1.15 \\
\hline Porcentagem de copa (\%) & 50 & 53.98 & 97.11 & 71.70 & 12.09 \\
\hline Formal de copa (adimensional) & 50 & 0.99 & 3.08 & 1.85 & 0.53 \\
\hline Grau de esbeltez (adimensional) & 50 & 9.17 & 35.17 & 16.34 & 5.74 \\
\hline
\end{tabular}

bém se encontram folhas com 2 (raro 3) pares de pinas. Em cada pina contam-se $12-30$ pares de folíolos opostos, oblongos (3 - 5 x 1 $1,2 \mathrm{~mm}$ ), muito aproximados entre si, glabros, de margem finamente ciliada e com nervuras bem visíveis nas faces, sobretudo em material seco. As flores, amarelo-claras, ocorrem em espigas mais longas do que as folhas $(5-12 \mathrm{~cm}) \mathrm{e}$ apresentam 10 estames de filamentos livres, com $5-6 \mathrm{~mm}$ de comprimento, bem como denso indumento no ovário e face interna das pétalas. Os legumes, de $10-18 \mathrm{~cm}$ de comprimento, são curvos, subtorulosos e de cor castanha, com manchas avermelhado-violáceas. As sementes, ovais $(7-8 \times 5-6 \mathrm{~mm})$ e achatadas, são castanhas.

\section{ANÁLISE DENDROLÓGICO-MORFO- MÉTRICA}

$\mathrm{O}$ estudo da morfometria e das relações morfométricas de espécies nativas é relativamente recente no Rio Grande do Sul, destacando-se, pelo pioneirismo, as contribuições de Durlo (1996, 2001), Durlo \& Denardi (1998, 2004) e Roman et al. (2009).

$\mathrm{Na}$ vegetação em estudo, chama atenção, de início, as grandes dimensões das árvores e, principalmente, a forma da copa de alguns indivíduos, que foge aos padrões referidos na literatura para Prosopis affinis.

Com relação à altura, os inhanduvás do parque do Loreto variam de 2,9 a 8,5m (Tabela 2), valores semelhantes aos referidos por Burkart ${ }^{9}$ (3 a $8 \mathrm{~m})$ e Izaguirre \& Beyhaut $^{10}(2,5$ a $8 \mathrm{~m}$, com média de $4 \mathrm{~m}$ ) para a mesma espécie.

Comparado aos inhanduvás do Parque Estadual do Espinilho, vê-se que os do Loreto são consideravelmente mais altos, pois das 286 árvores investigadas por Galvani (2003) em Barra do Quaraí, apenas 6 incluem-se na classe de altura superior (entre 4 e $5 \mathrm{~m}$ ), ficando a maioria dos indivíduos nas classes de $2-3 \mathrm{~m}$ (103 indivíduos), de $1-2 \mathrm{~m}$ (67 indivíduos) e de 3 $4 \mathrm{~m}(65 \text { indivíduos })^{11}$. Sobre este ponto, aliás, cabe ressaltar que nenhuma das árvores medidas por Galvani alcança, sequer, a altura média observada no parque do Loreto $(5,2 \mathrm{~m})$. Para os limites do Rio Grande do Sul, deste modo, podese afirmar que os exemplares de maior porte $-\mathrm{e}$ presumivelmente mais velhos - se encontram em São Vicente do Sul.

Para a Argentina, país onde o inhanduvá apresenta ampla área de ocorrência e chega a designar, inclusive, um dos distritos ${ }^{12}$ da "Pro-

9 BURKART, A. Leguminosae (= Fabaceae), Leguminosas. In: BURKART, A.; BURKART, N.T. de; BACIGALUPO, N.M. Flora Ilustrada de Entre Ríos (Argentina). Buenos Aires: I.N.T.A., 1987. p. 471.

${ }^{10}$ IZAGUIRRE, P., BEYHAUT, R. Las Leguminosas en Uruguay. Montevideo: Editorial Hemisferio Sur, 2003. p. 95.

${ }^{11}$ GALVANI, 2003. Op. cit., p. 79.

${ }^{12}$ Distrito del Ñandubay, segundo CABRERA \& WILLLINK (1973). 
TABELA 3 - Valores estatísticos da regressão entre DAP e altura total das árvores.

\begin{tabular}{|l|c|c|c|c|c|}
\hline \multicolumn{1}{|c|}{ FUNÇÃO } & $\begin{array}{c}\text { Constante } \\
\text { (Coef. a) }\end{array}$ & $\begin{array}{c}\text { Coeficiente } \\
\mathrm{b}\end{array}$ & $\mathrm{R}^{2}$ & $\begin{array}{c}\text { Erro } \\
\text { padrão }\end{array}$ & $\begin{array}{c}\text { Nível de } \\
\text { Sig. F }\end{array}$ \\
\hline Linear & 3,24 & 0,0546 & 0,43 & 0,92 & 0.0000 \\
\hline Logarítmica & $-1,07$ & 1,796 & 0,43 & 0,92 & 0.0000 \\
\hline
\end{tabular}

víncia del Espinal”, Tortorelli (1956) refere-se à espécie como árvore de "tercera o cuarta magnitud", por alcançar, com freqüência, de 8 - 12m de altura; Biloni (1990), por sua vez, descreve o inhanduvá como árvore mediana, de $10-15 \mathrm{~m}$ de altura. Vale notar que estes dois autores indicam um porte significativamente maior do que o presentemente verificado em São Vicente do Sul.

Outro aspecto digno de nota nos inhanduvás do Loreto é o diâmetro avantajado do tronco, observado em numerosos indivíduos. De acordo com a Tabela 2, vê-se que o DAP varia de 8,9 a $74,0 \mathrm{~cm}$, com média de $35,7 \mathrm{~cm}$. Para comparação, vale lembrar que de 118 indivíduos medidos no Parque Estadual do Espinilho, em Barra do Quaraí, apenas 2 apresentaram diâmetro entre 30 e $35 \mathrm{~cm}$, a classe superior observada por Galvani (2003); no mesmo trabalho, o autor encontrou 35 inhanduvás com diâmetros entre 15 e $20 \mathrm{~cm}$, seguida pelas classes de $10-$ $15 \mathrm{~cm}$ (29 indivíduos), de $5-10 \mathrm{~cm}$ (27 indivíduos), de $20-25 \mathrm{~cm}$ (13 indivíduos) e, finalmente, pela classe inferior, que reúne arvoretas de até $5 \mathrm{~cm}$ de diâmetro (12 indivíduos) ${ }^{13}$.

$\mathrm{Na}$ literatura argentina, Dimitri et al. (2000) citam diâmetros de até $50 \mathrm{~cm}$ para os troncos de inhanduvá; Tortorelli (1956), por sua vez, considera este valor como máximo para a espécie, ressaltando que são mais freqüentes as árvores de até $40 \mathrm{~cm}$ de DAP. No caso do Uruguai, Izaguirre \& Beyhaut (2003) referem diâmetros de 30 a $40 \mathrm{~cm}$, para a mesma espécie.

Dos 50 indivíduos do parque do Loreto presentemente investigados, 9 apresentam DAP

${ }^{13}$ GALVANI, F.R., 2003. op. cit., p. 80. superior a $50 \mathrm{~cm}$ (Tabela 1 e Figura 6), o que permite afirmar, com toda a segurança, que é nesta população que se encontram os troncos de maior diâmetro já registrados para a espécie, pelo menos no Rio Grande do Sul.

À semelhança da altura, anteriormente comentada, o diâmetro notavelmente grande de alguns troncos, que chega a ultrapassar, inclusive, os valores máximos atribuídos para a espécie na literatura platina, também aponta para a ocorrência natural do inhanduvá em São Vicente do Sul; sobre este ponto, resta acrescentar que não existe suporte histórico sobre a introdução da espécie pelo Homem branco e, muito menos, pelos índios que habitaram a região no passado (Marchiori et al., 2010).

A correlação positiva entre DAP e altura dos inhanduvás é demonstrada pelas curvas de regressão da Figura 2. Os valores indicados na Tabela 3 indicam que as funções linear e logarítmica se equivalem, pois apresentam coeficiente de determinação $\left(R^{2}\right)$ e erro padrão idênticos.

A altura de copa (Hc) e, sobretudo, a percentagem de copa $(\mathrm{Pc})$ permitem analisar uma das peculiaridades morfológicas mais notáveis nos inhanduvás do parque do Loreto, comparado a outras ocorrências no Estado. O primeiro destes parâmetros, expresso em metros, é obtido pela simples diferença entre a altura total da árvore $(\mathrm{H})$ e a altura da primeira bifurcação $(\mathrm{L})$ : $\mathrm{Hc}=\mathrm{H}-\mathrm{L}$.

De carga informativa semelhante, a percentagem de copa $(\mathrm{Pc})$ oferece, todavia, a vantagem de expressar um aspecto mais facilmente reconhecível na natureza - a altura da copa $(\mathrm{H}$ - L) em relação ao corpo ou altura total da árvore $(\mathrm{H})-$, expressa em percentagem: $\mathrm{Pc}=(\mathrm{H}$ $-\mathrm{L}) / \mathrm{H} \times 100$. 
TABELA 4 -Valores estatísticos da regressão entre DAP e área de copa.

\begin{tabular}{|l|c|c|c|c|c|}
\hline $\begin{array}{c}\text { FUNÇÃO } \\
\Downarrow\end{array}$ & $\begin{array}{c}\text { Constante } \\
\text { (coef. a) }\end{array}$ & $\begin{array}{c}\text { Coeficiente } \\
\mathrm{b}\end{array}$ & $\mathrm{R}^{2}$ & $\begin{array}{c}\text { Erro } \\
\text { padrão }\end{array}$ & $\begin{array}{c}\text { Nível de } \\
\text { Sig. F }\end{array}$ \\
\hline Linear & -24.84 & 1.87 & 0.71 & 17.38 & 0.0000 \\
\hline Logarítmica & -150.85 & 55.28 & 0,59 & 20.82 & 0.0000 \\
\hline
\end{tabular}

Na Tabela 2, vê-se que os inhanduvás do parque do Loreto distinguem-se por terem copas altas, com média de $71,70 \%$, um mínimo de $53,98 \%$ e valor máximo de $97,11 \%$ da altura total. Em 24 dos 50 indivíduos da população, esta percentagem ultrapassa a $70 \%$ e, em seis deles, a 90\% da altura da árvore (Tabela 1), valores que se manifestam na arquitetura da copa como traço distintivo, de fácil reconhecimento fisionômico. Os padrões corimbiforme ${ }^{14}$ e achatado $^{15}$, muito característicos nos inhanduvás de Barra do Quaraí e comumente citados na literatura como típicos da espécie, não podem, deste modo, ser atribuídos às árvores em estudo; para as mesmas, resultam mais adequados os termos "copa em sombrinha", ou copa tendente a hemisférica.

Se os inhanduvás do Loreto apresentam copas definidas como altas, o fuste das árvores

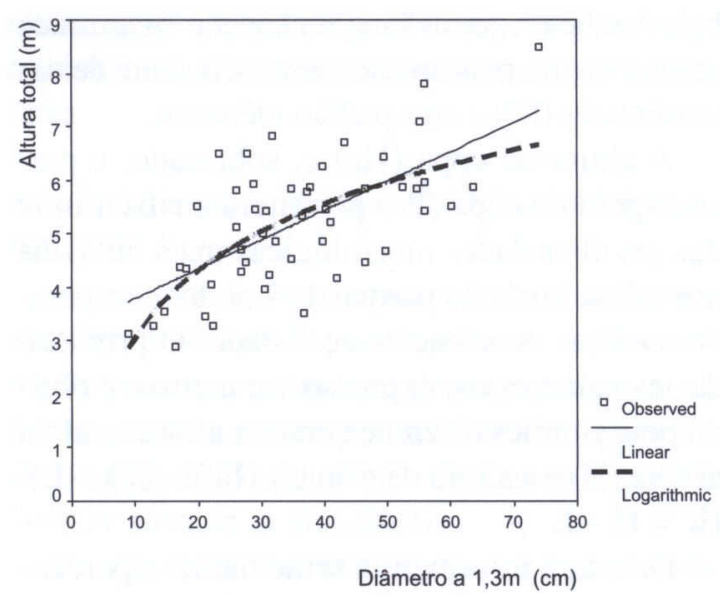

FIGURA 2 - Curvas de regressão entre o DAP e a altura total das árvores.

${ }^{14}$ Termo usado por MARCHIORI (1997).

15 Termo usado por BURKART (1987). (diâmetro até a primeira bifurcação) é relativamente baixo, distinguindo-se, igualmente, sob este aspecto morfológico, do padrão mais encontradiço nas árvores de Barra do Quaraí. Vale salientar, ain$\mathrm{da}$, que no Parque do Loreto não se observa nenhuma correlação entre o diâmetro à altura do peito (DAP) e a altura da primeira bifurcação no tronco das árvores (Figura 3).

O grau de esbeltez (GE), obtido pela razão entre a altura da árvore $(\mathrm{H})$ e o seu DAP (GE = H/DAP), expressa a estabilidade do tronco e, por conseguinte, da própria árvore. No caso dos inhanduvás do Loreto, os valores encontrados são muito baixos ${ }^{16}$, comparados a espécies de florestas nativas e plantadas, assemelhando-se, todavia, ao verificado em árvores de formações abertas, tais como savanas. A título de informação, vale citar que em árvores florestais nativas não são raros graus de esbeltez superiores a 100 e, até mesmo, 170, como os encontrados em in-

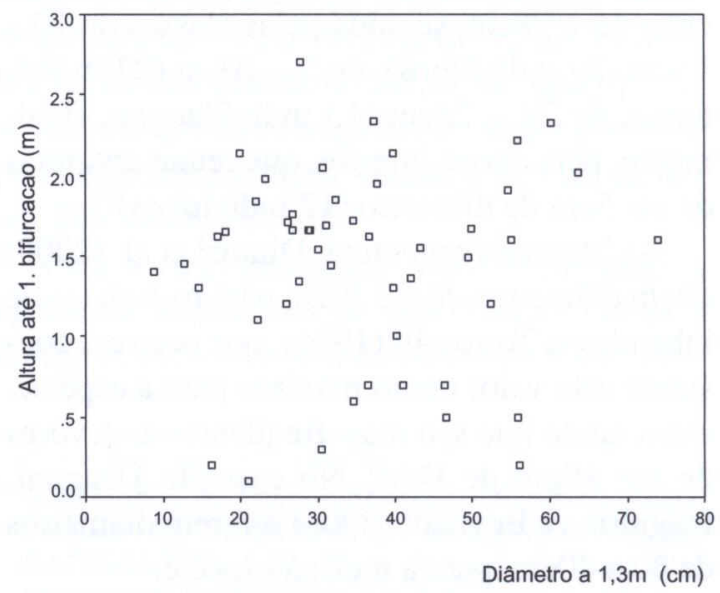

FIGURA 3 -: Plotagem dos dados de diâmetro e altura até a primeira bifurcação. 16 Variam de 5,73 a $161,7 \mathrm{~m}^{2}$, com média de $41,92 \mathrm{~m}^{2}$ (Ta-
bela 2). 


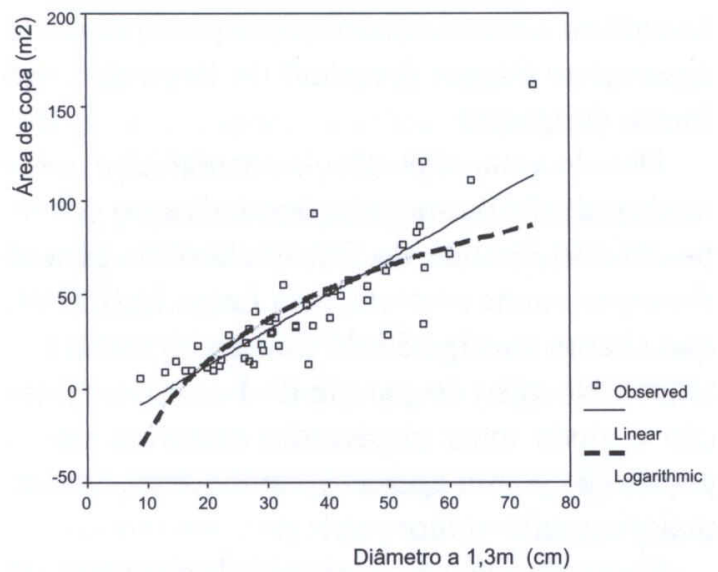

FIGURA 4 - Curvas de regressão entre DAP e área de copa.

divíduos de Cordia trichotoma (Vell.) Arráb. ex Steud. (Louro-pardo), por Durlo (1996) e Roman et al. (2009).

Igualmente característicos, no material em estudo, são os valores elevados de diâmetro (Dc) e área de copa (Ac), contrariamente ao observado em outras ocorrências da espécie no Estado. A respeito destes parâmetros, cabe observar que os valores excepcionalmente altos do inhanduvá $\mathrm{n}^{\circ} 46(14,4 \mathrm{~m}$ de diâmetro de copa e área de $161,7 \mathrm{~m}^{2}$ ) podem ser atribuídos à idade avançada da árvore, uma vez que a mesma cresce em meio a um grupo de indivíduos (Figura 1). No inhanduvá com a segunda maior área de copa (indivíduo $n^{\circ} 45$ ), vê-se que seu menor DAP não guarda proporcionalidade com a redução da área de copa ${ }^{17}$, apesar da árvore crescer isoladamente, sem competição alguma com outros inhanduvás (Figura 1).

A correlação entre diâmetro à altura do peito (DAP) e área de copa dos inhanduvás (Ac) é demonstrada pelas curvas de regressão da Figura 4. Vê-se, no gráfico, que a função linear mostra-se mais ajustada do que a logarítmica, fato comprovado pelo maior coeficiente de de-

\footnotetext{
${ }^{17}$ No inhanduvá de $\mathrm{n}^{\circ} 46$, com DAP de $74 \mathrm{~cm}$, a copa mede $161,7 \mathrm{~m}^{2}$; no de n. 45 , com DAP de $63,7 \mathrm{~cm}$, a copa é proporcionalmente menor $\left(110,3 \mathrm{~m}^{2}\right)$; no primeiro caso a árvore cresce em grupo, no segundo, isoladamente.
}

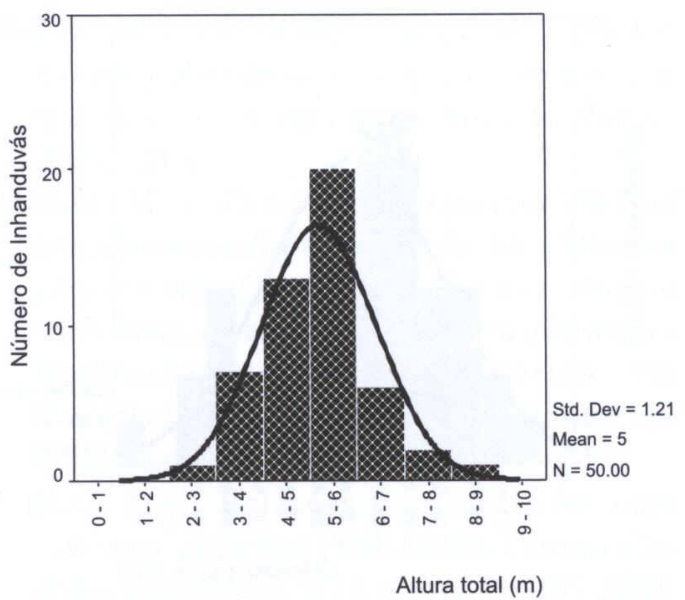

FIGURA 5 - Histograma do número de inhanduvás por classe de altura.

terminação $\left(\mathrm{R}^{2}\right)$ e menor erro padrão, indicados na Tabela 4.

Como relação entre o diâmetro de copa (Dc) e a altura de copa $(\mathrm{Hc})$, o índice formal de copa $(\mathrm{Fc})$ define, matematicamente, a forma da copa das árvores: $\mathrm{Fc}=\mathrm{Dc} / \mathrm{Hc}$.

O valor mínimo observado na população, de 0,99 (Tabela 2), indica que este indivíduo apresenta diâmetro e altura de copa praticamente iguais, o que determina um padrão hemisférico, facilmente reconhecido na natureza. $\mathrm{O}$ valor máximo observado, de 3,08 (Tabela 2), indica que a copa desta árvore apresenta diâmetro um pouco maior do que 3 vezes a sua altura, o que configura um padrão em sombrinha. É entre estes dois extremos - copa hemisférica e copa em sombrinha - que se distribuem os 50 inhanduvás do parque do Loreto.

Os índices formais de copa presentemente observados comprovam, matematicamente, que os termos "amplo e estendido", "achatado" e "corimbiforme", tradicionalmente aplicados a Prosopis affinis, e facilmente reconhecidos nos indivíduos do Parque Estadual do Espinilho (Barra do Quaraí), não se ajustam às árvores de São Vicente do Sul.

Os histogramas das Figuras 5 e 6 fornecem elementos esclarecedores para a análise da vitalidade do parque, ou seja, sobre a expectativa de permanência dos inhanduvás na região. Em 


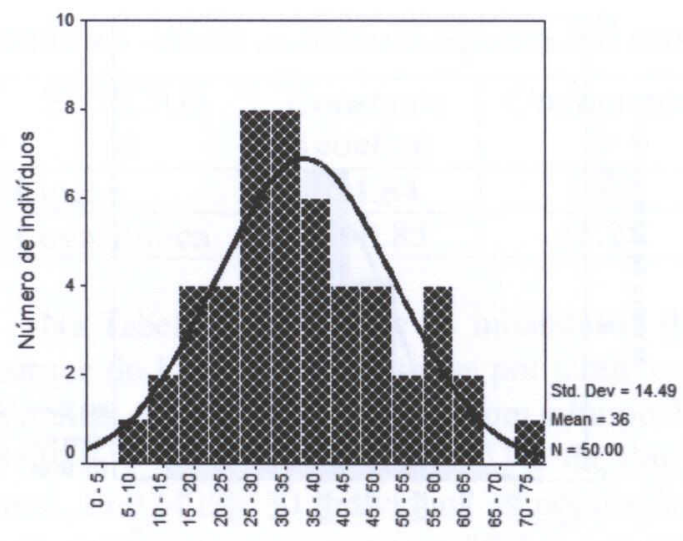

Diâmetro a $1,3 \mathrm{~m}(\mathrm{~cm})$

FIGURA 6 - Histograma do número de indivíduos por classe de diâmetro.

ambos os histogramas vê-se que não existem plantas pequenas, com menos de $2 \mathrm{~m}$ de altura $\mathrm{e}$ $5 \mathrm{~cm}$ de DAP. A ausência de indivíduos jovens indica que existem problemas no recrutamento de eventuais plântulas germinadas a partir de sementes. A sobrevivência do parque, em outras palavras, encontra-se em situação crítica e sua conservação, a médio e longo prazos, demanda cuidados especiais. $\mathrm{O}$ problema reside, provavelmente, no pisoteio e predação de brotações exercidos pelo gado, notadamente ovino.

Como situação ideal, recomenda-se o cercamento de parte ou de toda a área com inhanduvás, com vistas a proteger os indivíduos remanescentes in situ e criar condições favoráveis para a germinação de sementes e recrutamento de mudas. Igualmente recomendáveis são a colheita de sementes, a produção de mudas em viveiro e sua distribuição a proprietários interessados no cultivo da espécie, como forma de multiplicar este material genético.

Outro ponto a salientar, no caso da Figura 6, é que a distribuição diamétrica não apresenta a forma de "J" invertido, típica de florestas naturais, com numerosos indivíduos nas classes diamétricas inferiores e relativamente poucos nas classes de maior diâmetro. Sobre este ponto, vale salientar que Galvani (2003) também encontrou a mesma distribuição presentemente descrita no Parque Estadual do Espinilho, em Barra do Quaraí.

Devido a sua importância econômica e acentuada redução das populações nativas, o governo do Rio Grande do Sul declarou o gênero Prosopis imune ao corte, pela Lei n. 11.026/97, que alterou o artigo 33 do Código Florestal Estadual. No caso do parque do Loreto, a proteção é ainda mais importante, uma vez que a população possui apenas 50 indivíduos, em sua maioria muito velhos.

Desconhecido pela comunidade científica até pouco tempo, os inhanduvás do parque do Loreto encontram-se isolados de outras populações da mesma espécie ${ }^{18}$ por algumas centenas de quilômetros, fato que acresce importância à preservação de seu material genético. Apesar das eventuais diferenças geradas por este isolamento ao longo do tempo, há que se reconhecer que os inhanduvás de São Vicente do Sul distinguem-se mais por aspectos morfométricos relativos ao porte e copa das árvores, do que por diferenças botânicas de valor taxonômico reconhecido.

Boa parte destas peculiaridades morfométricas pode decorrer, tão simplesmente, de diferenças nas condições ambientais vivenciadas pelas distintas populações. No caso dos inhanduvás do parque do Loreto, os solos, além de profundos e arenosos, não apresentam salinidade nem argilas expansivas, aspectos marcantes no parque de Barra do Quaraí e de efeitos bem conhecidos na fisiologia e crescimento das árvores. Sobre este ponto, aliás, o campo ainda não foi desbravado, seguindo aberto a novas e mais aprofundadas pesquisas.

\section{CONCLUSÕES}

O estudo de aspectos dendrológicos e morfométicos dos inhanduvás do parque do Loreto (São Vicente do Sul) mostra que:

\footnotetext{
${ }^{18}$ É o caso dos parques do Jarau, no município de Quaraí, e do "Parque Estadual do Espinilho", em Barra do Quaraí.
} 
- A identidade botânica do material corresponde a Prosopis affinis Spreng. (Fabaceae), espécie conhecida popularmente como inhanduvá.

- A população do parque do Loreto está reduzida a 50 indivíduos, que são muito velhos, em sua maioria.

- É no parque do Loreto que se encontram os inhanduvás de maior porte (altura e DAP), existentes no Rio Grande do Sul.

- Alguns indivíduos analisados ultrapassam os diâmetros referidos na literatura para Prosopis affinis, motivo pelo qual, muito provavelmente, os troncos de inhanduvás mais robustos também se encontram em São Vicente do Sul.

- Na vegetação em estudo, a copa dos inhanduvás varia do padrão em sombrinha à forma hemisférica, não servindo, para os mesmos, os termos "amplo e estendido", "corimbiforme" e "achatado", constantes na literatura sobre a espécie.

\section{LITERATURA CITADA}

BILONI, J.S. Arboles autoctonos argentinos. Buenos Aires: Tipográfica Ed. Argentina, 1990. 335 p.

BRUSSA SANTANDER, C.A.; GRELA GONZÁLEZ, I.C. Flora arbórea del Uruguay. Con énfasis en las especies de Rivera y Tacuarembó. Montevideo: COFUSA, 2007. 542 p.

BURKART, A. Materiales para una monografia del género Prosopis (Leguminosae). Darwiniana, v. 4 , n. 1, p. 57-128, 1940.

BURKART, A. Leguminosae. In: CABRERA, A.L. Flora de la Provincia de Buenos Aires. Buenos Aires: Coleccion cientifica del I.N.T.A., 1967. p. 394-647.

BURKART, A. Leguminosae (= Fabaceae), Leguminosas. In: BURKART, A. Flora Ilustrada de Entre Ríos (Argentina). Buenos Aires: Coleccion cientifica del I.N.T.A., 1987. p. 442 - 738.

CABRERA, A.L.; WILLINK, A. Biogeografia de America Latina. Washington: Secretaria General de la Organización de los Estados Americanos (OEA), 1973. 117 p.
DIMITRI, M.J.; LEONARDIS, R.F.J.; BILONI, J.S. El nuevo libro del árbol: especies forestales de la Argentina oriental.Buenos Aires: El Ateneo, 2000. 124 p.

DURLO, M.A. Zuwachsuntersuchungen und Einzelbaumwachstumsmodelle für Cabralea glaberrima, Cedrela fissilis und Cordia trichotoma in sekundären Laubmischwäldern Südbrasiliens. Wien: Universität für Bodenkultur, 1996. 175 f. Dissertation zur Erlangung des Doktorgrades.

DURLO, M.A. Relações morfométricas para Cabralea canjerana (Well.) Mart. Ciência Florestal, Santa Maria, v. 11, n. 1, p. 141-149, 2001.

DURLO, M.A.; DENARDI, L. Morfometria de Cabralea canjerana, em mata secundária nativa do Rio Grande do Sul. Ciência Florestal, Santa Maria, v. 8, p. 55-66, 1998.

DURLO, M.A.; DENARDI, L. Modelagem da copa de Cedrela fissilis Vellozo. Ciência Florestal, Santa Maria, v. 14, p. 79-89, 2004.

GALVANI, F.R. Vegetação e aspectos ecológicos do Parque Estadual do Espinilho, Barra do Quaraí, RS. 132 f. Porto Alegre: Universidade Federal do Rio Grande do Sul, 2003. Tese de Doutorado (Programa de Pós-Graduação em Botânica).

IZAGUIRRE, P.; BEYHAUT, R. Las Leguminosas en Uruguay. Montevideo: Editorial Hemisferio Sur, 2003. 301 p.

MARCHIORI, J.N.C. Dendrologia das Angiospermas. Leguminosas. Santa Maria: Ed. UFSM, 1987. $199 \mathrm{p}$.

MARCHIORI, J.N.C.; ALVES, F. da S. O inhanduvá (Prosopis affinis Spreng.) no Rio Grande do Sul. 3 - Parque da Cabanha do Loreto, São Vicente do Sul. Balduinia, Santa Maria, n. 25, p. 22-31, 2010.

MORENO, J.A. Clima do Rio Grande do Sul. Porto Alegre: Secretaria da Agricultura - Diretoria de Terras e Colonização, 1961. 42 p.

NIMER, R. Clima. Geografia do Brasil. Região Sul. Rio de Janeiro: IBGE, 1977. p. 35-79.

NUÑEZ, C.O.; CANTERO, J.J. Fabaceae Lindl. In: BARBOZA, G.E.; CANTERO, J.J.; NUÑEZ, C.O.; ESPINAR, L.A. Flora medicinal de la Provincia de Córdoba (Argentina). Pteridófitas y Antófitas silvestres o naturalizadas. Córdoba: Museo Botânico, 2006. p. 679-759. 
ROMAN, M.; BRESSAN, D.A.; DURLO, M.A. Variáveis morfométricas e relações interdimensionais para Cordia trichotoma (Vell.) Arráb. ex Steud. Ciência Florestal, v. 19, p. 473480, 2009.

STRECK, E.V.; KÄMPF, N.; DALMOLIN, R.S.D.;
KLAMT, E.; NASCIMENTO, P.C. do; SCHNEIDER, P.; GIASSON, E.; PINTO, L.F.S. Solos do Rio Grande do Sul. Porto Alegre: EMATER/RS - ASCAR, 2008. 222 p.

TORTORELLI, L.A. Maderas y bosques argentinos. Buenos Aires: Editorial ACME, 1956. 910 p. 